\title{
A gestão urbana e ocupação em áreas de preservação permanente na cidade de Guarapuava (PR): o caso do arroio do Carro Quebrado
}

\author{
Management in urban areas and occupation of permanent preservation \\ areas in the city of Guarapuava (PR): the case of the stream Carro Quebrado
}

Nilmar Pussinini'

\section{Resumo}

$\mathrm{Na}$ cidade, o capitalismo se reproduz de forma muito dinâmica. É nela, que o ambiente, antes natural, torna-se cada vez mais artificial, ou seja, ambiente construído. Com isso, cada vez mais o relevo e os rios são cobertos pelas edificações. Neste contexto, falar de áreas de preservação permanente nas cidades correlacionando-as com as políticas públicas que gerenciam e gestam as cidades, bem como o processo de produção e reprodução do espaço urbano é algo complexo, pois envolve muitos interesses, principalmente dos agentes que o produzem. Neste contexto o trabalho visa discutir as condições socioambientais das áreas de preservação permanente na cidade. As áreas de preservação permanente são preocupações da temática ambiental relacionadas à sociedade e ao ambiente. Preservá-las é uma preocupação social, que envolve a discussão de conceitos como a natureza, preservação, e qualidade de vida no meio ambiente urbano. Através de imagens de satélite, fotografias aéreas e dados coletados, diretamente no campo, buscamos localizar e espacializar as informações, de forma a obter uma visão de conjunto da distribuição do curso hídrico estudado, juntamente com as condições das áreas ao seu em torno que, a priori, deveriam ser destinadas à preservação permanente. Em Guarapuava, há uma importante rede de drenagem, contudo, os rios urbanos estão praticamente todos canalizados, e aqueles que ainda preservam seu curso original, estão degradados pelo lançamento de esgoto e assoreamento. Pensar condições e formas de planejamento e de gestão pública voltados para a conservação dessas áreas que a priori seriam de preservação, é um caminho para a recuperação dos cursos hídricos que ainda resistem à expansão da cidade.

Palavras-chave: áreas de preservação permanente; meio ambiente urbano; gestão urbana; ocupações em áreas de risco.

I Graduado em Geografia; Mestrando em Geografia pela Universidade Estadual de Maringá, UEM; Bolsista do Conselho Nacional de Desenvolvimento Científico e Tecnológico, CNPq; Endereço:Avenida Colombo, 5790, CEP: 87.020-900, Maringá, Paraná, Brasil; E-mail: nilmar6@hotmail.com

Recebido para publicação em 31/0I/20II e aceito em II/04/20II

Ambiência Guarapuava (PR) v.7 n.I p.I33 - I53 Jan./Abr. 20II ISSN I808 - 025।

DOI:10.5777/ambiencia.2011.01.02rc 


\section{Abstract}

In the urban area, capitalism increases really dinamically, it is in this place that the natural environment becomes more and more artificial, that is, a built environment. Thus, the natural envionment and rivers have been replaced by buildings. In this context, discussing about preservation of natural environment in the urban area, correlating them with mainstream politics, as well as the creation of urbanism, is a complex subject, due to different interests involved. The present job consists in an undergraduate final paper of a techer education course on Geography studies. The investigation aimed at discussing the preserved environmental area conditions in the urban area, since they are related to the social and environmental issues. Maintaining these areas is a social issue, consequently, it demands discussions on concepts concerning nature, preservation, and quality of life in cities. Through images via satellite, aerial photos and data collection fom the field, we searched for defining widelly the spatial area and the distribuition of the focused stream. Moreover, we dedicated studies on the surroundings of the stream, which, a priori, should be permanentely preserved. In the city of Guarapuava-PR, there is an important drainage system, however, urban streams are almost totally in pipelines, and those ones which preserves their original course are degradated due to sewerage and silting up. In this way, it is a must to think of planning ways and conditions, as well as state manegement, for preserving the mentioned areas, aiming at recovering the streams that resist the urban growing.

Keywords: permanent preservation areas; urban environment; urban manegement; unsafeness areas.

\section{Introdução}

Os problemas ambientais urbanos têm se ampliado significativamente nos últimos anos. Esta preocupação, antes pouco discutida, hoje é amplamente debatida por praticamente todas as classes da sociedade, havendo também uma mobilização dos meios de comunicação em geral, evidenciando a dimensão do problema. Muitos fatores são responsáveis por tal generalização dos debates, fatores que vão desde a escala local acerca da poluição dos rios, por exemplo, até os de ordem global como a relacionada ao aquecimento global. Nota-se, nesse sentido, uma espécie de temor ambiental, visto que tal temática preocupa e mobiliza a sociedade como um todo.

A materialização dos problemas ambientais na paisagem urbana é perceptível, através do acúmulo de "lixo", ocupação em áreas de risco, poluição do ar e das águas, entre outros. No que se refere aos rios urbanos estes expressam nitidamente este conflito da 
sociedade com a natureza. Aqueles que ainda não foram canalizados são: objetos de destino de resíduos, de efluentes sem tratamento, edificações nas margens ou nas nascentes que deveriam estar sendo preservadas.

Quando a ocupação se dá por população que tem um elevado poder aquisitivo, este acaba sendo tomado como amenidade paisagística, agregando maior valor para aquele determinado espaço, já que estas populações, quando habitam áreas a margem de lagos ou rios, o escolhem porque são elementos de fator estético, agregando-as como elemento de valoração da propriedade privada.

O mesmo não se pode dizer das populações mais carentes, que ocupam as margens dos cursos hídricos por serem públicos, fato que facilita a ocupação. Pelo poder público, geralmente, estas ocupações são tomadas como clandestinas, ou ocupações irregulares. Quando as moradias são precárias, e sem a devida infraestrutura oferecem riscos a população e, como esteticamente não obedece aos padrões de "beleza" da sociedade capitalista, a área é desvalorizada no mercado.

Com isso, fica claro o conflito: como preservar os rios na cidade, onde a lógica é a ocupação máxima do seu território? Além disso, como combinar políticas de preservação a despeito da lógica da desigualdade de direitos na apropriação da cidade?

É neste contexto que se insere a pesquisa que deu origem a este trabalho, na qual buscamos discutir as condições das áreas de preservação permanente na cidade de Guarapuava-PR e sua relação com a gestão e o planejamento urbano, tendo como recorte espacial de pesquisa, a sub-bacia do arroio do Carro Quebrado, afluente da bacia do rio Cascavel - curso hídrico que drena a maior parte do sítio urbano da cidade.

\section{DEGRADAÇÃO AMBIENTAL EM ÁREAS DE PRESERVAÇÃO PERMANENTE NAS CIDADES}

Os conflitos entre sociedade e natureza podem ser analisados seguindo a perspectiva analítica de Spósito (2003), que faz referência a uma análise da dimensão temporal, implicada no social e no ambiental, cujas dimensões de avanço e aprimoramento se dão de maneira diferente. Cada vez que o social avança sobre o natural, apropriando e explorando-a, a escala temporal natural se vê corrompida pela escala da sociedade, que tem um avanço técnico, científico bem mais acelerado que os processos e dinâmicas naturais, fazendo assim com que essa intervenção no natural se dê, cada vez, de maneira mais rápida e intensa. Segundo a autora,

Os problemas urbanos como o da erosão, desmoronamento de encostas, assoreamento de cursos d'água [...] são na essência problemas decorrentes do descompasso entre o tempo da natureza -o das eras geológico-e do tempo da sociedade - o dos anos, dias e horas. (SPÓSITO, 2003, p. 96).

De acordo com, Gonçalves (1995), esse modelo de desenvolvimento instaurado nos países de terceiro mundo, ou em desenvolvimento, como no Brasil, consolidou os padrões culturais de consumismo desenfreado, típicos de países de primeiro mundo, a posse de eletrodomésticos, e o uso de automóveis tornaram-se símbolos de desenvolvimento e riqueza, ocasionando, com isso, uma série de consequências nocivas para o meio ambiente, como as altas taxas de emissões de gases poluentes, provenientes das indústrias e dos próprios produtos por elas fabricados como os automóveis. 
Em 1960, o Brasil tinha cerca de 60 milhões de habitantes, sendo que $46 \%$ dessa parcela residiam nas cidades, ou seja, 28 milhões de habitantes citadinos. Em 1990 esse número salta para 115 milhões, de um total aproximado de 148 milhões de brasileiros. Isso significa que, em apenas trinta anos, a população urbana brasileira aumentou de 28 para 115 milhões, "transformando a questão urbana no principal problema sócio-ambiental do país. Uma vez que reflete, mais do que qualquer outra as consequências perversas do atual modelo de desenvolvimento." (GONÇALVES, 1995, p. 323).

Outro fato marcante do desenvolvimento urbano brasileiro é que o Estado sempre priorizou os projetos voltados para a infra-estrutura das cidades, como transportes, comunicações e energia, deixando para um segundo, (ou terceiro!) plano as questões de investimentos sociais em habitação e saneamento básico, tornando-as suscetíveis aos impactos ambientais.

Também ressaltamos as contribuições de Guerra sobre as respostas naturais as alterações sofridas, afirmando que: "À medida que as árvores são cortadas, ruas são asfaltadas, casas e prédios são construídos, encostas são impermeabilizadas, rios são canalizados, ocorre toda uma série de respostas geomorfológicas" (GUERRA e MARÇAL, 2006, p.30). Respostas essas que vêm na forma de enchentes, deslizamento de encostas, alagamentos entre outros, assumindo assim, um caráter catastrófico que, muitas vezes, não são resultantes de processos naturais, mas sim da ocupação irregular e, neste caso, o ambiente está dando uma resposta à agressão que vem sofrendo.

Daí afirmar-se que o ambiente urbano "consolidou-se como um ambiente de baixa qualidade, justapondo algumas poucas estruturas urbanas marcadas pelo consumo desenfreado e pelos desperdícios"(BITOUN, 2003, p. 302). Estas poucas estruturas concentram-se em bolsões de classe média ou alta.

Em seu conjunto, a cidade se configura por um número muito mais expressivo de periferias urbanas, com espaços isolados aquém de infra-estrutura, saneamento básico, com ocupações em áreas impróprias, como por exemplo, as de fundo de vale, ou próximas aos cursos hídricos.

Diante disso, não resta aos pobres das cidades outra alternativa senão erguer suas habitações precárias, barracos, nas encostas instáveis ou em fundos de vales, onde o desmatamento e o acúmulo de lixo contribuem para que as nossas mais corriqueiras chuvas de verão, com as enxurradas se transformem num grande pesadelo. (GONÇALVES, 1995, p. 324).

Podemos dizer que a transformação da natureza (industrialização, ampliação das vias de transporte e circulação, edificações, pavimentação, e muitas outras engenharias produzidas nas cidades) seja justificada pelo "desenvolvimento" que traz benefícios para a população, mas a apropriação destes é muito desigual.

Segundo Bitoun (2003), esta população menos favorecida economicamente ocupa áreas que as exclui e isola nas periferias ou em áreas impróprias para a habitação, o que os colocam como os produtores da degradação ambiental urbana que será mais cedo ou mais tarde refletida sobre eles mesmos, com uma intensidade maior. Eles são, na essência, os próprios produtores dos problemas ambientais que os afetarão.

As famílias pobres foram assim os próprios artesãos da degradação da 
natureza, quando de modo recorrente, vem construindo a cidade como podem, ocupando terrenos que, pela racionalidade técnica deveriam ser mantidos em estado natural. (BITOUN, 2003, p. 300).

Este estado conflituoso acerca da moradia nos ambientes urbanos remete-nos a fazer uma reflexão mais ampla sobre o próprio processo de produção e reprodução do espaço urbano. Ou seja, é preciso entender a gênese do processo de apropriação do solo urbano, bem como sua dinâmica e princípios para assim podermos compreender o atual e complexo quadro de déficit habitacional nos ambientes citadinos.

\section{A importância das Áreas de Preservação Permanente}

Áreas de preservação permanente, segundo o código florestal de 1965, são: florestas ou demais áreas de vegetação naturais situadas ao longo dos rios ou de outro qualquer curso de água, desde seu nível mais alto, ou seja, a montante, até a sua foz em faixa marginal. Essa faixa marginal varia de acordo com a dimensão do curso de água. Conforme o código, a dimensão da faixa de proteção marginal é:

1) de 30 (trinta) metros para os cursos d'água de menos de 10 (dez) metros de largura;

2) de 50 (cinquenta) metros para os cursos d'água que tenham de $10(\mathrm{dez})$ a 50 (cinquenta) metros de largura;

3) de 100 (cem) metros para os cursos d'água que tenham 50 (cinquenta) metros a 200 (duzentos) metros de largura;

A existência e conservação dessas áreas são de grande importância para os rios, pois sem elas são inúmeros os danos que podem ocorrer, desde a erosão das margens, movimento de massas (desbarrancamento), aceleração dos processos de assoreamento e comprometimento do fluxo de escoamento, até a consequente redução da qualidade das águas dos mesmos, e da própria qualidade de vida da população.

Porém, tais especificações caem em contradições antes mesmo de serem aplicadas, uma vez que as diferentes esferas legislativas estabelecem dimensões distintas sobre essas áreas. Revela-se assim um problema instaurado na própria ordem jurídica, pois esta calcada no legalismo liberal, muitas vezes influenciada pelos interesses econômicos, torna-se ineficaz na aplicação das leis vigentes. Segundo Fernandes (2004), o grande desafio dos juristas e demais cientistas sociais e administradores públicos, urbanistas e ambientalistas é o de problematizar o Direito para colocá-lo no "mundo da vida", tendo em vista que o Direito tem criado tantos conflitos quantos os que têm se proposto a resolver.

Em especial, tal discussão crítica sobre o Direito deve buscar compreender o papel determinante que a ordem jurídica tem tido na determinação do padrão de acesso a terra urbana e a moradia, bem como das condições de utilização dos recursos naturais. Em outras palavras, na determinação dos processos combinados de segregação socioespacial e degradação socioambiental. (FERNANDES, 2004, p. 104).

De uma maneira geral, o crescimento urbano depreda e inibe a expansão das áreas de preservação permanente e, mesmo quando protegidas por lei, muitas vezes, encontram-se brechas legislativas que só beneficiam aquele que se apropriou da área, ou seja, o sistema tende a privilegiar sempre o depredador, pois a verdade é 
que o interesse dos grupos econômicos continua prevalecendo e influenciando a ação do Estado e da implantação de políticas públicas mais justas no que toca aos assuntos ambientais.

Desta forma, o cumprimento da legislação não é algo fácil, pois implica jogos de poder e, neste caso, nem sempre é a qualidade ambiental do lugar que prevalece sobre os interesses econômicos. "A implementação de condições adequadas de aplicação das leis vai depender da criação de melhores mecanismos de administração pública e, acima de tudo, de um sistema judicial mais eficiente." (FERNANDES, 2004, p. 113).

\section{O PROCESSO DE PRODUÇÃO E REPRODUÇÃO DO ESPAÇO URBANO}

Segundo Corrêa (1995, p. 7), o espaço urbano é um produto social resultado de inúmeras ações através do tempo. Ele é composto por agentes que produzem e consomem este espaço. Estes fazem e refazem este espaço de acordo com seus interesses, e são: os proprietários dos meios de produção (grandes industriais e empresas comerciais), proprietários fundiários, promotores imobiliários, o Estado e Grupos sociais excluídos ou emergentes na sociedade. "A ação destes agentes é complexa, derivando da dinâmica da acumulação do capital, das necessidades mutáveis de reprodução, das relações de produção e dos conflitos de classe que dela emergem".

Os proprietários dos meios de produção, em razão da dimensão e intensidade das suas atividades, são os grandes consumidores do espaço urbano. Necessitam de amplas e baratas porções de terra. Os proprietários fundiários atuam no sentido de obter a maior renda de suas propriedades. Buscam a transformação de espaços antes considerados rurais ou sem ocupação, em terra urbana, sob forma de loteamentos. Seu interesse é no valor de troca da terra e não no seu valor de uso. Sobre os agentes imobiliários que modelam o espaço urbano, David Harvey (1980, p. 139) afirma que "Há numerosos e diversos atores no mercado de moradia, e cada grupo tem um modo distinto de determinar o valor de uso e o valor de troca”. Ressaltando que, para Harvey, na economia capitalista, o solo urbano é tratado como mercadoria e, como qualquer outra mercadoria, possui um valor composto por duas dimensões: o valor de uso (utilidade que determinado objeto possui) e o valor de troca (poder de compra que a posse de um objeto transmite).(HARVEY,1980).

O Estado, por sua vez, atua na organização espacial da cidade. Sua atuação tem sido complexa e variável tanto temporal quanto espacialmente, refletindo na dinâmica da sociedade da qual ele é parte constituinte. Embora sua inserção seja legitimada no sentido de tornar os direitos e deveres mais equitativos, este tende a atender os interesses dos grupos dominantes que, via de regra, possuem maior força política. (CORRÊA, 1995).

$\mathrm{Na}$ sociedade capitalista, verificam-se sociais no que se refere ao acesso e posse de bens e serviços produzidos socialmente. A habitação é um exemplo que, apesar de ser um direito da população, independente de nível social, não é acessível a todos. Com isso, essa parcela desfavorecida tende a procurar outras maneiras para suprir suas necessidades habitacionais, muitas vezes gerando favelas, e ocupações irregulares. Corrêa (1995) ainda conclui que, ao produzirem favelas, 
invadindo terrenos públicos ou privados, os grupos excluídos da sociedade capitalista, ou seja, a população com menor renda produz o seu próprio espaço urbano, tornando-se efetivamente um agente modelador deste espaço.

Entender como a atuação desses agentes influencia no processo de acesso a moradia das cidades é uma das nossas intenções, procurando compreender como a lógica da apropriação e de uso do solo exclui, e fragmenta as cidades, associando a garantia ao solo urbano à situação econômica, e transformando a questão fundiária urbana em algo meramente mercadológico. Tornase necessário, portanto, uma reflexão sobre o próprio modo de se pensar a cidade, para assim, melhor compreendermos o processo de produção e reprodução de seu espaço.

Daremos início às discussões em torno de como a cidade vem sendo pensada, ora como quadro físico, ora como meio ambiente urbano, ignorando o conteúdo da prática sócio-espacial que lhe dá forma e conteúdo. Tais fatos nos revelam que vivemos não somente em uma crise na cidade, sinalizada pelos intensos processos de segregação urbana, mas também que nos deparamos com uma crise teórica.

As transformações das cidades vão destruindo as relações de vizinhança, esvaziando as ruas, deteriorando as praças, transformando os lugares em locais de compra. Os bairros se apresentam cada vez mais transformados, derrubam-se casas para se construir edifícios e com eles a verticalização da cidade. As praças dão lugar a estacionamentos, derrubam-se árvores que nascem em meio às ruas, provocando um processo que acaba produzindo o vazio do cheio. "É o fundamento do que chamo de espaço amnésico, um espaço sem referencias e inóspito à vida, porque limita e restringe as modalidades do uso". (CARLOS, 2007, p. 58). Tudo se parece inexoravelmente, pois a ditadura do moderno impõe-se de modo incontestável.

A ocupação da cidade, submetida pela existência da propriedade privada do solo, é produto da expansão da urbanização capitalista, fazendo com que o acesso à cidade seja mediado constantemente pelo setor imobiliário. "A disseminação da propriedade da terra na cidade esta assentada, nas sociedades capitalistas, no direito à propriedade, isto é, no acesso privado a vida na cidade. [...] Portanto, a produção do espaço urbano metropolitano realiza o espaço enquanto mercadoria" (CARLOS, 2007, p.73). Neste contexto, o espaço torna-se fragmentado, condicionado e explorado a partir dos interesses do mercado, e é produzido e reproduzido enquanto espaço de dominação.

\section{A questão do habitar a cidade...}

O plano da habitação nas cidades revela o nível vivido enquanto prática sócio-espacial concretizadas no modo de como as pessoas se apropriam de um espaço fragmentado pelas estratégias dos empreendedores imobiliários, como é o caso das cidades atualmente. Deste modo, a cidade inteira está submetida ao valor de troca, o que significa dizer que os modos possíveis de apropriação devem realizar-se nos limites da propriedade privada do solo urbano, que delimita o acesso dos cidadãos à moradia, da mesma forma que determina outros usos. (CARLOS, 2007).

$\mathrm{O}$ espaço da habitação não pode ser reduzido ao plano ideológico da casa, pois assim entendendo, o plano de habitar é muito mais amplo. A partir da sua casa, o cidadão usa outros lugares, como a rua, os parques, 
praças, etc. "Assim a prática sócio-espacial, no plano vivido, aparece como modo de apropriação dos lugares da cidade, onde se estabelecem os vários momentos da vida cotidiana para além da casa" (CARLOS, 2007, p. 93).

A segregação se origina da propriedade privada, da lógica em que se instaurou nas cidades atuais, de privação e mercantilização do solo urbano, condicionando o acesso à terra ao poder aquisitivo, e negando ao cidadão o direito da moradia. A segregação é, assim, uma negação do urbano e da vida urbana e assume, varias facetas indicando processos diferenciados apesar de justapostos. Deste modo, a segregação assume e ocorre ligada a vários elementos e pode ser. A) Espontânea: a partir de uma diferenciação de renda. De um lado estão os luxuosos e "seguros" condomínios fechados, marcados por uma população de alta renda, enquanto de outro lado, aumentam expressivamente as periferias e favelas, com uma população carente e desprovida dos recursos da "cidade urbanizada". Deste modo, "O mercado fundiário, da cidade, distribui a população no espaço baseado na racionalidade da propriedade privada" (CARLOS, 2007, p. 96). B) Segregação Programada: que assim denominada por Henry Lefebvre, se realiza pela intervenção estatal através das políticas urbanas. Isto é, a intervenção do Estado no espaço, seja através das construções de infraestrutura, ou seja, pelas políticas urbanas que incentivam o deslocamento das atividades, transformando as funções dos lugares, diferencia e transforma as funções destes e, por sua vez, a sua valorização e especulação. C) Mercantilismo do solo urbano: nesta dimensão, as estratégias imobiliárias se inscrevem no espaço revelando a lógica do valor de troca da terra, revelando a intercambialidade fundiária urbana. (CARLOS, 2007).

Neste contexto reducionista, a questão da habitação se enquadra nos interesses mercadológicos, menosprezando as necessidades básicas de moradia das populações menos abastadas, financeiramente falando. Reproduz-se assim, o chamado de anti-cidade, as manchas urbanas, no qual a estratégia imobiliária volta-se para a negação dos direitos de cidade para essas áreas, menos valorizadas. Mesmo o Estado que, por obrigação institucional, deve assegurar a moradia aos cidadãos, fracassa constantemente em suas ações para amenizar a situação de déficit habitacional, quadro encontrado facilmente nas cidades atualmente. Assim afirmado, pois este, também está mais preocupado com as questões econômicas do que as referentes ao bem estar, e a qualidade de vida da população. Nesse sentido, se torna relevante a discussão sobre a gênese dos problemas habitacionais no Brasil, bem como a questão da mobilização social em prol da reivindicação de seu direito da habitação justa e de qualidade.

\section{Os movimentos sociais e a gênese dos problemas habitacionais brasileiros}

Procuraremos trabalhar neste texto, abordando o fenômeno da luta pelo acesso à moradia sob o prisma sociológico, pois observamos que o que temos, no cenário atual, é a incursão de milhares de pessoas, em sua maioria com baixo poder aquisitivo, numa ação coletiva e ilegal, buscando assim obter um bem considerado essencial para a sobrevivência humana, a habitação.

A gênese dessa problemática pode ser explicada a partir do desenvolvimento do capitalismo no Brasil, mais precisamente a partir da década de 1930, época que o 
país sofre um grande impulso fazendo com que grandes massas de mão-de-obra se concentrassem nos centros urbanos. $\mathrm{O}$ drástico rebaixamento do valor do trabalho dessas classes, gerou um setor populacional bastante numeroso, altamente empobrecido e incapaz de participar do mercado dentro de padrões considerados mínimos.

O desenvolvimento histórico brasileiro foi marcado pela atuação do Estado, que estimulou e até mesmo financiou o desenvolvimento acelerado do capitalismo. Esta situação chegou também ao setor agrícola que, por sua vez, produziu a liberação de mão-de-obra camponesa para os centros urbanos, geralmente já em processo de empobrecimento e despreparo para receber tal demanda.

O contexto urbano da época tirou, dessa massa recém chegada, a possibilidade de participação em determinados setores do mercado. No caso da habitação a participação tornou-se ainda mais difícil. A regulamentação formal do uso do espaço urbano é outro agravante, bem como a taxação fiscal das áreas de moradia. $\mathrm{O}$ custo do pagamento dos serviços púbicos não podia ser arcado por este setor mais empobrecido da população. $O$ resultado desse processo é que esta massa humana explica a taxa de 87 milhões de desnutridos, além das altas taxas de mortalidade infantil e de outros indicadores de miséria nacional. (AZEVEDO, 2002, p. 22).

As numerosas ocupações irregulares presenciadas atualmente são fruto de todo este processo de desenvolvimento histórico do capitalismo brasileiro, bem como das políticas públicas adotadas pelo Estado para conter, ou resolver tal situação. Ocorridas as ocupações, os participantes deparam-se com a necessidade de desenvolver estratégias para resistir às artimanhas postas em prática pelo Estado para retomar a organização do espaço. Por um lado, as autoridades públicas encarregadas de gerir os serviços públicos têm de dar respostas imediatas às reivindicações das massas populares, mas, como isto não é possível, os problemas se acumulam e o impasse se mantém. Por outro lado, exatamente porque é preciso impedir que essa prática "selvagem" e "anárquica" se alastre, cria-se um círculo vicioso entre Estado/massa.

A ocorrência do conflito revela uma relação tensa entre os setores empobrecidos e o Estado. "O movimento aparece então, não como uma ação particularista, irracional e anárquica, mas como uma resposta às duras condições de vida a que está submetida grande parte da população brasileira" (AZEVEDO, 2007, p. 26).

De acordo com Azevedo (2007), a atuação estatal no Brasil, sempre demonstrou, historicamente, uma tendência a privilegiar a implantação acelerada de uma estrutura industrial, sem se preocupar com as condições de sobrevivência e reprodução da imensa massa humana que veio para operar esse sistema. Assim, as históricas e constantes invasões de terrenos e loteamentos clandestinos são fenômenos originados dessa matriz. O desenvolvimento do capitalismo brasileiro gerou, com isso, uma numerosa massa social que sequer pode pagar o custo de existir legalmente, situação que exige um caminho alternativo, geralmente burlando a lei. Já que a ação estatal, aliada com a dinâmica capitalista gera um poder excludente, referindo-se a estas classes empobrecidas. "Este poder é desafiado pela massa empobrecida em busca de melhores condições de vida toda vez que relaxa o controle e a ação de seu aparato repressivo" (AZEVEDO, 2007, p. 33). 
As possíveis soluções para tal situação estariam relacionadas com um planejamento urbano que enfatizasse mais as questões sociais, como as ligadas à habitação, o bem estar da população e o cuidado com a conservação dos recursos naturais inseridos no espaço urbano, deixando de priorizar tanto as questões de aspecto econômico e financeiro como é feito atualmente.

\section{GESTÃO E PLANEJAMENTO URBANO: UMA APROXIMAÇÃO CONCEITUAL}

O conceito de gestão que se viu por muito tempo associado apenas às questões ligadas, por exemplo, à gestão empresarial, vem ganhando, a partir da década de 80, outras atribuições como: Gestão Territorial, Gestão Ambiental etc.

O termo tem sido utilizado como sinônimo de planejamento, equívoco que deveria ser revisto, por possuírem referenciais temporais distintos e também por se referirem a diferentes tipos de atividades (SOUZA, 2006).

De uma maneira intuitiva, planejar remete a pensar o futuro, "planejar significa tentar prever a evolução de um fenômeno [...] tentar simular desdobramentos de um processo, com o objetivo de melhor precaver-se contra prováveis problemas." (SOUZA, 2006, p.46). Por outro lado, gestão faz referência ao presente, gerir significa administrar uma situação dentro da disponibilidade dos recursos e visando atender as necessidades imediatas. "O planejamento é a preparação para a gestão futura, buscando-se evitar ou minimizar problemas e ampliar margens de manobras; e a gestão é a efetivação ao menos em parte das condições que o planejamento feito no passado ajudou a construir." (SOUZA, 2006, p.46).
Um importante papel destinado ao planejamento é, ainda, o de orientar os instrumentos metodológicos, administrativos, legislativos e de gestão para o desenvolvimento de atividades num determinado espaço e tempo, incentivando a participação institucional e dos cidadãos, induzindo a relações mais estreitas entre sociedade e autoridades locais e regionais. (SANTOS, 2004, p. 24).

Desta forma, a ênfase principal do planejamento está na tomada de decisões. Os elaboradores de planejamento procuram entender o espaço em todo seu contexto, não centrados em apenas um tema, mas procurando trabalhar com e entre os diversos atores que compõem o meio.

Sendo assim, os termos apresentados, são distintos, mas complementares. Tanto a gestão é algo indispensável, pois consiste em administrar os recursos e as relações de poder no presente momento, como abdicar o planejamento é aceitar a hipótese do caminho errado. Negar o planejamento é negar a possibilidade de escolher/prever o futuro. (SOUZA, 2006).

Diversos cientistas sociais são colaboradores para o planejamento urbano, em se tratando de países com uma ideologia de planejar bem concretizada. Além dos já clássicos arquitetos, engenheiros e urbanistas, alguns cientistas sociais como os geógrafos vêm ganhando espaço neste contexto, diferentemente do quadro brasileiro, onde ainda há a predominância dos profissionais $\mathrm{da}$ arquitetura atuando preferencialmente. Segundo Souza (2006), isto gera um duplo equívoco, pois, o profissional arquiteto ou urbanista, devido a sua formação carrega consigo uma gama de conhecimento técnicos e específicos, tendo com isso uma visão diferente daquele dos cientistas sociais. 
Enquanto o cientista social tenderá, ao lidar com o espaço urbano, a mobilizar o seu conhecimento a propósito das relações e dos processos sociais e dos condicionamentos espaciais [...], o arquiteto legitimamente, poderá derramar luz sobre aspectos funcionais e estéticos. (SOUZA, 2006, p. 57).

\section{Planejamento e gestão urbana no contexto da promoção do desenvolvimento sócio espacial}

Segundo a perspectiva de Souza (2006), as discussões sobre desenvolvimento têm se mostrado, a partir da segunda guerra mundial, quase sempre atreladas a outros termos como os: econômicos, teológicos e conservadores, o que torna usual a ideia de "desenvolvimento" como sinônimo de "desenvolvimento econômico", formando, com isso, uma base capitalista, entendendo que somente no mundo ocidental é que há desenvolvimento.

Para obter um verdadeiro desenvolvimento socioespacial na cidade, é preciso livrar-se do significado da expressão "desenvolvimento urbano", geralmente utilizado e associado aos discursos rotineiros de políticos, administradores e do público em geral, com o intuito de expandir espacialmente e tornar mais complexa a malha urbana, ou seja, transformar ambientes antes "intocados" ou pouco modificados, em ambientes com construções "modernas" e " o que acontece é que a linguagem ordinária é modelada por uma ideologia modernizante que é a versão urbana da ideologia do "desenvolvimento" capitalista em geral: desenvolver é dominar a natureza, fazer crescer, "modernizar". (SOUZA, 2006, p. 75, grifo nosso).
Para entender criticamente o desenvolvimento urbano, temos que tomar por princípio os dois objetivos do planejamento e da gestão urbanos, o da melhoria da qualidade de vida e o do aumento da justiça social, estes surgindo como instrumentos para um desenvolvimento menos agressivo, ambientalmente falando. Nesse sentido, o planejamento urbano/ambiental, torna-se uma, ou talvez a única, alternativa para alcançar tais objetivos.

\section{Planejamento ambiental e seus objetivos}

Pode-se notar que existem diferentes tipos de planejamento: o planejamento econômico, o planejamento físico, o Ecológico entre outros. Outra vertente, tenta simplificar as tipologias de planejamento. Para esses autores, há dois tipos básicos: o planejamento tradicional e o ambiental ou ecológico. Este último apresentaria uma abordagem de orientação sistêmica, priorizando os fins; seria então holístico. Em suma, o planejamento tradicional, enfoca as comunidades e sua população, o uso da terra, a economia e a infra-estrutura, através de metas, planos e regulamentos. Enquanto que o ambiental visa o ambiente biofísico onde vivem as pessoas e as comunidades, e analisa os efeitos das atividades de desenvolvimento e de outros planejamentos. (SANTOS, 2004). Auxilianos na compreensão dos dois tipos básicos de planejamento o quadro 01, representado abaixo.

O planejamento ambiental pode, nesse sentido, ser tratado como um instrumento de intervenção, e ter um caráter regulador sobre os processos de exploração do espaço e dos recursos naturais. Surgiria assim, o que 
denomina como "Capitalismo Ecológico", "que trata de incorporar o discurso da sustentabilidade da economia de mercado, no qual se consistem certa regulação e controle" (MAURO, 1997, p. 18). Aqui é possível pensar em uma articulação entre EconomiaSociedade-Estado e Meio-Ambiente.

\section{Instrumentos condicionantes para a aplicabilidade do planejamento ambiental}

A escolha do instrumento para aplicação do planejamento ambiental deve se dar em função de seus objetivos. $\mathrm{Na}$

Quadro I. Comparação entre o planejamento tradicional e o planejamento ambiental (CHAVEZ, 1994) apud Mauro, Cláudio Antônio de 1997

\begin{tabular}{|c|c|}
\hline Planejamento Tradicional & Planejamento Ambiental \\
\hline \multicolumn{2}{|l|}{ Objetivos } \\
\hline Privilegiar o crescimento; & Privilegiar a qualidade de vida; \\
\hline Gerar máxima eficiência econômica; & $\begin{array}{l}\text { Produzir para satisfazer as necessidades } \\
\text { básicas da população; }\end{array}$ \\
\hline & Gerar desenvolvimento regional harmônico; \\
\hline \multicolumn{2}{|l|}{ Concepção } \\
\hline $\begin{array}{l}\text { Setorial e parcial do desenvolvimento; } \\
\text { Linear: seleciona uma só opção; } \\
\text { Determinista: atua como suposto da } \\
\text { incerteza; }\end{array}$ & $\begin{array}{l}\text { Integral e sistêmica; } \\
\text { Múltiplas opções: busca a combinação e a } \\
\text { variedade; } \\
\text { Trabalha com a incerteza, a probabilidade e o } \\
\text { desconhecimento; }\end{array}$ \\
\hline \multicolumn{2}{|l|}{ Organização produtiva } \\
\hline $\begin{array}{l}\text { Promove formas de organização } \\
\text { empresarial mercantil; } \\
\text { Interessado só nos aspectos econômicos; }\end{array}$ & $\begin{array}{l}\text { Interessado nos aspectos econômicos, sociais } \\
\text { e naturais; }\end{array}$ \\
\hline \multicolumn{2}{|l|}{ Resolução de conflitos de interesses } \\
\hline $\begin{array}{l}\text { Não reconhece a existência destes } \\
\text { conflitos; por isso, não propõe ações para } \\
\text { superá-los; }\end{array}$ & $\begin{array}{l}\text { Reconhece a possibilidade da existência } \\
\text { destes conflitos no processo de } \\
\text { desenvolvimento integral; } \\
\text { Busca elementos para sua solução; }\end{array}$ \\
\hline
\end{tabular}

Fonte: MAURO, Antônio Cláudio, 1997 
maioria dos casos, são sinônimos desse tipo de planejamento os Zoneamentos, Estudos de Impacto Ambiental, Planos de Bacias Hidrográficas, Planos Diretores Municipais entre outras legislações de cunho ambiental vigentes, (melhor explicitado no quadro 0203). Estas formas deveriam ser associadas sempre aos planejamentos ambientais, já que são caminhos para se alcançar os objetivos e metas específicas por ele pretendidas.

Para tanto, os objetivos mais imediatos dos instrumentos serão, sobretudo, os seguintes: inibir a especulação imobiliária; propiciar uma boa qualidade ambiental (por meio da inibição do adensamento excessivo, da degradação do meio ambiente, [...]; induzir o rebaixamento geral do preço da terra; [..]; e garantir uma alocação espacial de recursos mais justa. (SOUZA, p. 320, 2006).

Com o amparo das determinações supracitadas, deparamo-nos com uma série de descumprimentos de tais normatizações, que resultaram no quadro de degradação encontrado nos centros urbanos de uma forma geral. Nesse sentido, os trabalhos como os aqui propostos apresentam-se como alternativas para que providências sejam tomadas, e assim se faça cumprir as leis que levem a punição dos responsáveis.

Em relação à cidade de Guarapuava (PR), local onde se encontra nossa área de estudo, esta situação não é diferente. Os processos de produção da cidade foram ocorrendo de acordo com diferentes interesses dos agentes modeladores deste espaço, sem haver a devida preocupação com os aspectos físicos do ambiente.

\section{A PRODUÇÃo DO ESPAÇO URBANO DE GUARAPUAVA}

O crescimento e a expansão urbana de Guarapuava estiveram atrelados, em princípio, à economia tropeira. Os interessados, por sua vez, adquiriam as "datas", que seriam os lotes urbanos oferecidos pelo poder público, onde construíam suas casas; mas continuavam

Quadro 2. Instrumentos condicionantes para a aplicabilidade do planejamento ambiental

\begin{tabular}{|l|l|}
\hline $\begin{array}{l}\text { Zoneamento } \\
\text { Ambiental }\end{array}$ & $\begin{array}{l}\text { Os zoneamentos ambientais são instrumentos que regulamentam o } \\
\text { uso do solo em determinada delimitação, (Zonas) proibindo alguns } \\
\text { usos e permitindo outros. Os pressupostos para tais determinações são } \\
\text { embasados em estudos das potencialidades, vocações e fragilidades naturais } \\
\text { identificadas na área referida. }\end{array}$ \\
\hline $\begin{array}{l}\text { Estudos de } \\
\text { Impactos } \\
\text { Ambientais }\end{array}$ & $\begin{array}{l}\text { Este instrumento trata de fazer uma avaliação sobre os possíveis impactos } \\
\text { ambientais que porventura virão a acontecer em determinada área, por } \\
\text { meio de uma ação antrópica. }\end{array}$ \\
\hline $\begin{array}{l}\text { Ministério das } \\
\text { Cidades }\end{array}$ & $\begin{array}{l}\text { O Ministério das Cidades tem como missão principal, segundo o próprio } \\
\text { ministério, combater as desigualdades sociais, transformando as cidades em } \\
\text { espaços mais humanizados, ampliando o acesso da população à moradia, } \\
\text { ao saneamento básico e ao transporte. (MINISTÉRIO DAS CIDADES, } \\
\text { 2003). A ele compete tratar da política de desenvolvimento urbano e das } \\
\text { políticas setoriais de habitação, saneamento ambiental, transporte urbano } \\
\text { e trânsito. }\end{array}$ \\
\hline
\end{tabular}

Nota: Instrumentos condicionantes para a aplicabilidade do planejamento ambiental. Org. PUSSININI, Nilmar. 2008. 
Quadro 3. As legislações como instrumentos de gestão

\begin{tabular}{|l|l|}
\hline Código Florestal & $\begin{array}{l}\text { A lei no } 7.803 \text {, de } 18 \text { de julho de 1989, determina em seu artigo 20 que } \\
\text { "são áreas de preservação permanente, as florestas e demais formas } \\
\text { de vegetação situadas: a) ao longo dos rios ou de qualquer outro curso } \\
\text { d’água, em faixa marginal cuja largura mínima será de } 30 \text { metros para } \\
\text { os rios com até } 10 \text { metros de largura (...); c) nas nascentes, qualquer que } \\
\text { seja a situação topográfica num raio de } 50 \text { metros de largura". }\end{array}$ \\
\hline Código de Pesca & $\begin{array}{l}\text { A lei n. 221,28/02/1967, sobre o lançamento de efluentes das redes de } \\
\text { esgoto e os resíduos líquidos ou sólidos pelas indústrias, neste caso só } \\
\text { poderão ser lançados às águas quando não as tornarem poluídas. E ainda } \\
\text { caracteriza poluição como: "qualquer alteração das propriedades físicas, } \\
\text { químicas ou biológica das águas, que possa constituir prejuízo, direta ou } \\
\text { indiretamente, à fauna e flora aquática". }\end{array}$ \\
\hline $\begin{array}{l}\text { R e s o 1 u ç ã o o } \\
\text { Conama }\end{array}$ & $\begin{array}{l}\text { A resolução no 1, de 23/01/1986, que considera os impactos ambientais } \\
\text { "qualquer alteração das propriedades físicas, químicas e biológicas do } \\
\text { meio ambiente, causada por qualquer forma de matéria ou energia } \\
\text { resultante das atividades humanas. }\end{array}$ \\
\hline $\begin{array}{l}\text { Co n s ti tu ição o o } \\
\text { Federal }\end{array}$ & $\begin{array}{l}\text { A constituição Federal determina em seu artigo 225, que "todos têm } \\
\text { direito ao meio ambiente ecologicamente equilibrado, bem de uso } \\
\text { comum ao povo e essencial à sadia qualidade de vida, impondo-se ao } \\
\text { Poder Público e à coletividade o dever de defendê-lo e preservá-lo para } \\
\text { as presentes e futuras gerações." }\end{array}$ \\
\hline
\end{tabular}

Nota: Quadro 3. As legislações como Instrumentos de Gestão. Org. PUSSININI, Nilmar. 2008.

a morar em suas residências da fazenda, permanecendo em suas casas da cidade apenas em dias festivos, para fazer compras, eleições etc. (SILVA,1995).

Contudo, foi a partir de meados do século $\mathrm{XX}$ que se constatou um crescimento urbano mais perceptível, dado em virtude do fim da era tropeira na região, devido à invibialidade que se tornou para os vaqueiros levarem o seu gado do Sul até São Paulo, em tempos de surgimento de ferrovias e estradas que cortam a região. (SILVA, 1995).

Com isso, passaram a surgir novos loteamentos em áreas até então de pequenas propriedades de caráter rural. Por volta de 1950 verificou-se como tendência a criação de novas vilas junto a até então estrada Foz - Curitiba que passava, levando à formação novos bairros e lotes com tendência a oeste
(SILVA, 1995). Já entre as décadas de 60 e 90, (Figura 1), sua expansão deu-se pelas mais variadas áreas da cidade, sobretudo nas porções norte e oeste, com loteamentos cada vez mais distantes do centro destinados à população de baixa renda.

Toda esta expansão horizontalizada da cidade acarretou na formação de loteamentos e ocupações em áreas impróprias para habitação, ou ainda em áreas de preservação ambiental, como por exemplo, os fundo de vales, e áreas de próximas a nascentes ou a rios urbanos, desrespeitando, assim, as legislações ambientais vigentes, tanto na constituição federal, como estadual e municipal com o plano diretor da cidade.

Ressalta-se que estes, surgem também como instrumentos de gestão produzidos pelas próprias cidades, ou seja, além dos já 
elucidados anteriormente (quadro 02-03) os planos diretores têm grande importância para que as prefeituras das cidades apliquem, com o amparo desses instrumentos, as intenções de um planejamento e de uma gestão enfatizando as questões ambientais.

Quanto à legislação ambiental vigente em Guarapuava, o plano diretor da cidade nos apresenta, no cap. II, determinações referentes aos parcelamentos do solo e ocupações em áreas urbanas.

Art. 5o - Não será permitido o parcelamento do solo:

I. Em terrenos alagadiços e sujeitos a inundações, antes de tomadas as providências para assegurar o escoamento das águas;

II. Nas nascentes, mesmo os chamados "olhos d'água", seja qual for a sua situação topográfica, antes de tomadas as devidas providências;

V. Em terrenos em fundos de vale (...)

VI. Em terrenos situados em áreas de preservação florestal e ecológica;

VIII.As áreas que possuírem quaisquer nascentes, lagos, reservatórios naturais ou artificiais e cursos d' água, bem como áreas que possuírem vegetação nativa (...). (PLANO DIRETOR, 2006).

Ainda há uma delimitação de áreas que deveriam se encontrar sem qualquer ocupação, como também nos evidencia o plano diretor em seu Artigo $7^{\circ}$.

Art. $7^{\circ}$ - As áreas descritas nos incisos abaixo são passíveis de parcelamento, mas constituem áreas não edificáveis:

I - nas áreas de fundos de vale, as larguras mínimas não edificáveis serão de 15 (quinze) metros ao longo dos cursos d'água com menos de 5 (cinco) metros de largura e 30 (trinta) metros ao longo dos cursos d'água que tenham mais de 5(cinco) metros de largura, $[\ldots]$.
II - ao redor de lagoas e lagos (naturais ou represados), contados a partir da margem medindo horizontalmente, em faixa marginal cuja largura mínima será de $15 \mathrm{~m}$ (quinze metros);

III - áreas de florestas e demais formas de vegetação naturais situadas ao longo de rios, ao redor de lagoas, nas nascentes, no topo de morros, nas encostas, nas bordas, conforme dispõe o Código Florestal.

Ficam assim definidas, segundo a legislação municipal, delimitações de áreas de preservação no ambiente urbano de Guarapuava, sendo eles situados ao longo dos rios urbanos existentes no interior da malha urbana da cidade.

\section{As Áreas de Preservação Permanente em Guarapuava-PR}

O município de Guarapuava, até a década de 70, era praticamente rural.Porém este cenário foi se alterando a partir de mudanças políticas e econômicas que ampliaram o êxodo rural, propiciando o aumento da massa populacional urbana, havendo, assim, um crescimento desordenado e com consequências drásticas para este meio (GOMES, 2005).

A cidade, que tinha em 1970, 16,54 $\mathrm{km}^{2}$ de área, passou em 2005, para 70,98 km². Com essa considerável expansão horizontal aliada às necessidades de ocupação de todo o contingente que havia chegado, intensificou as ocupações em locais impróprios, como por ex. os fundo de vales, reduzindo e, em muitos casos, acabando com as matas ciliares dos rios urbanos (GOMES, 2005).

Em Guarapuava há uma importante rede de drenagem, contudo, os rios urbanos estão praticamente todos canalizados, e aqueles que ainda preservam seu curso original, estão degradados pelo lançamento de esgoto e 


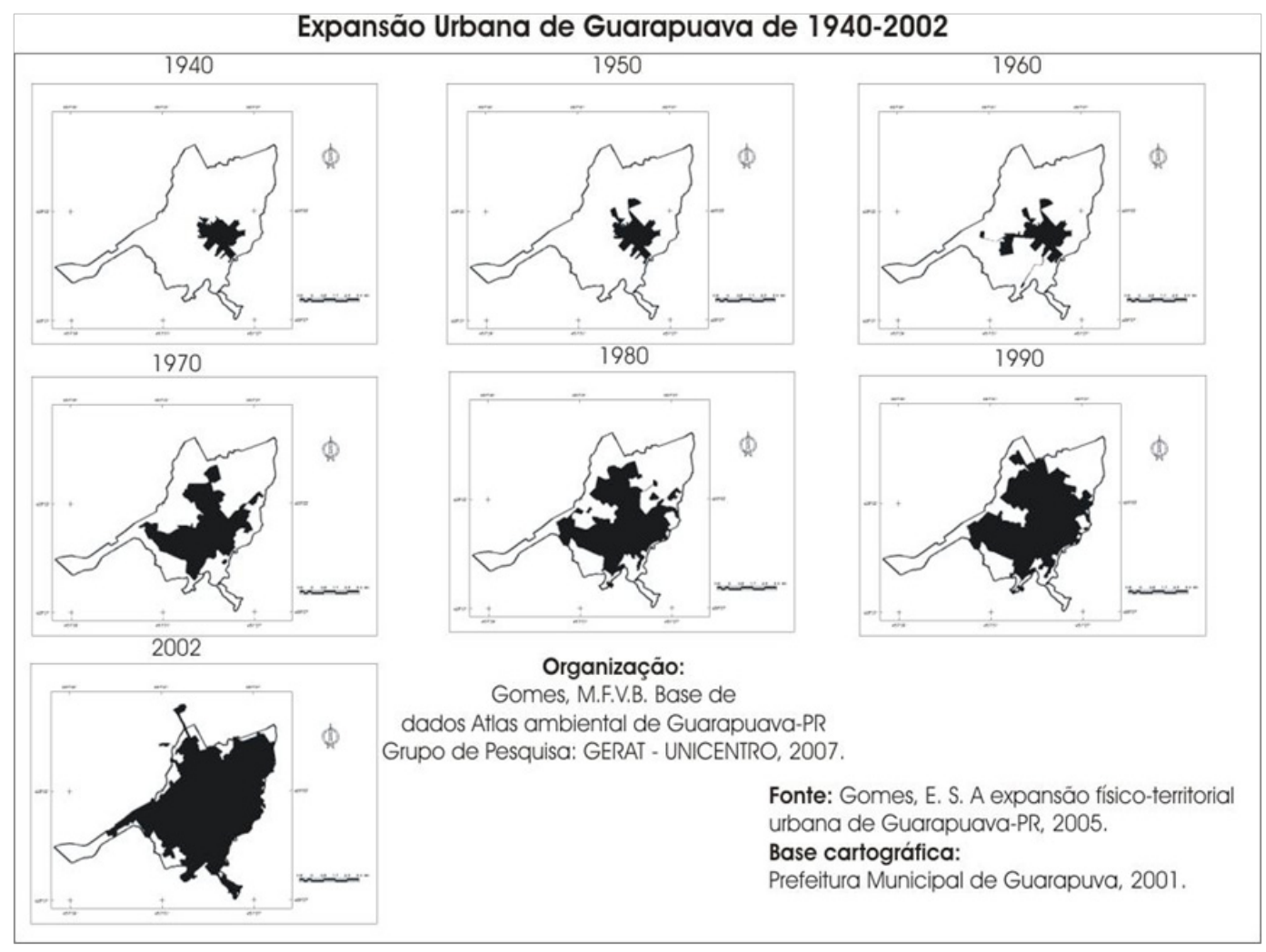

Figura I. Expansão físico-territorial de Guarapuava - 1940 a 2002

assoreamento. Pensar condições das áreas que, a priori, seriam de preservação, é um caminho para a recuperação dos cursos hídricos que ainda resistem à expansão da cidade.

$\mathrm{Na}$ figura 2, Área Urbana de Guarapuava, podemos observar que, ao entorno dos rios, há um predomínio de construções e poucas áreas de vegetação, o que tem contribuído para sua degradação e redução da qualidade e quantidade das águas, temática que está diretamente ligada às intenções da pesquisa.

No seu perímetro urbano, há a ocorrência de quatro bacias hidrográficas, conforme figura 3 (Bacias Hidrográficas Urbanas de Guarapuava). A principal delas é a Bacia do Rio Cascavel, pois compreende a maior parte do espaço urbano. Em nosso estudo, ater-nos-emos em analisar as áreas de preservação permanente, situadas ao longo da sub-bacia do Arroio do Carro Quebrado - afluente do rio Cascavel.

Outra forma de analisarmos a situação das Áreas de Preservação Permanente, no recorte escolhido, é através do quadro 4, exposto abaixo, que nos evidencia a depredação em que se encontram as áreas situadas ao longo do arroio do Carro Quebrado, pois, nele, podemos identificar que as áreas que deveriam ser destinadas à preservação, são destinadas a edificações, depósitos de lixo, canalizações, etc.

Para uma melhor confiabilidade dos dados empíricos, obtidos diretamente em campo, foi produzida a figura 4 , contendo os pontos exatos onde foram captadas as imagens explícitas no quadro 4, além de constar uma delimitação da área da sub- 


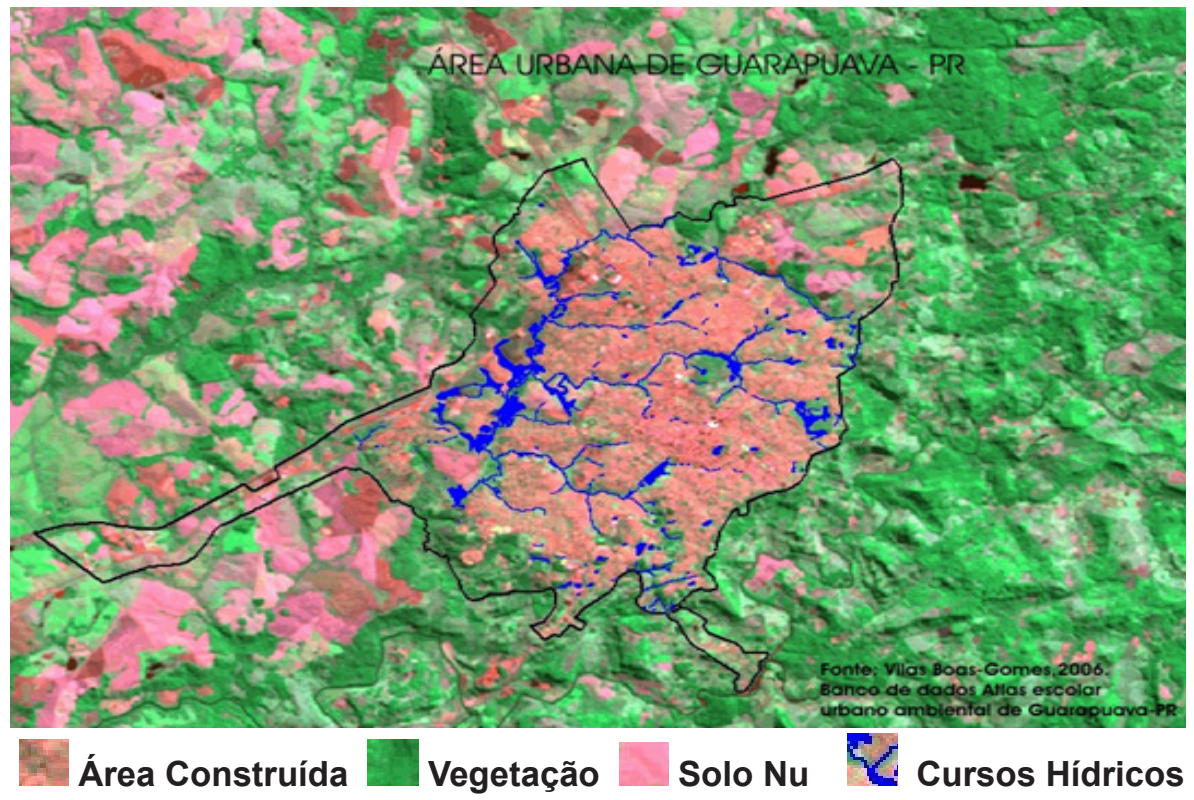

Figura 2. Área Urbana de Guarapuava (PR)

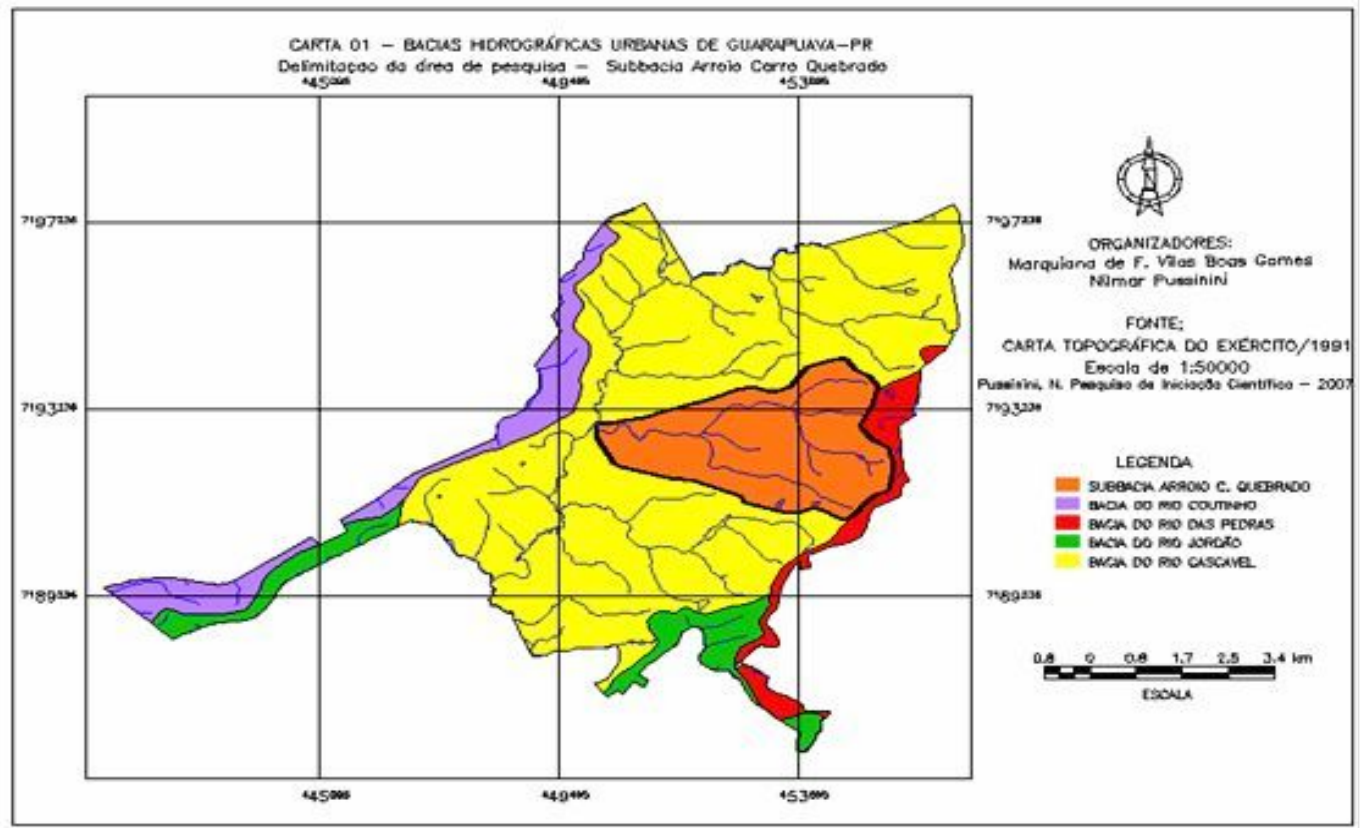

Figura 3. Bacias Hidrográficas Urbanas de Guarapuava (PR) 
Quadro 4. Caracterização das áreas de preservação permanente no arroio do Carro Quebrado Guarapuava (PR)

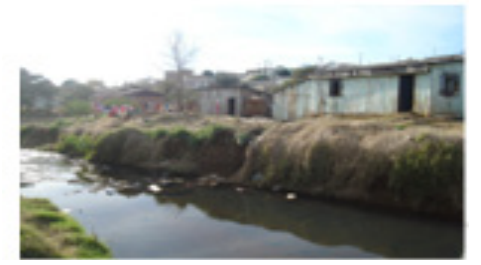

Imagem acusando a ocupação irregular para moradia, prática que além de gerar muito lixo, acelera os processos de assoreamento do rio devido ao movimento de massas, como se observa na fotografia.

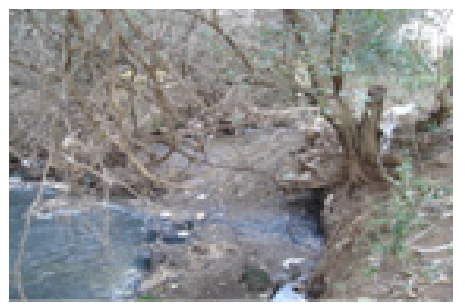

Percebe-se muito lixo e alto grau de poluição na água. O fluxo natural de escoamento do curso hídrico está seriamente comprometido pelo despejo de resíduos nesta área.

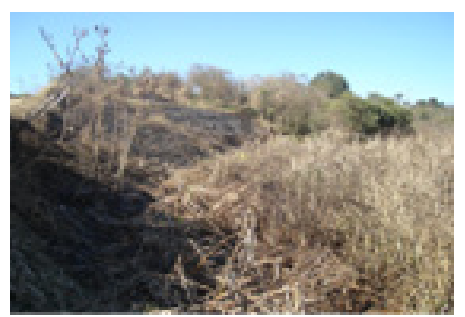

Imagem captada bem próxima à nascente do arroio. Observa-se, contudo nesta área, a presença da prática de queimadas, destruindo assim as formas de vegetação e empobrecimento do solo.

Org. PUSSININI, Nilmar. 2008.

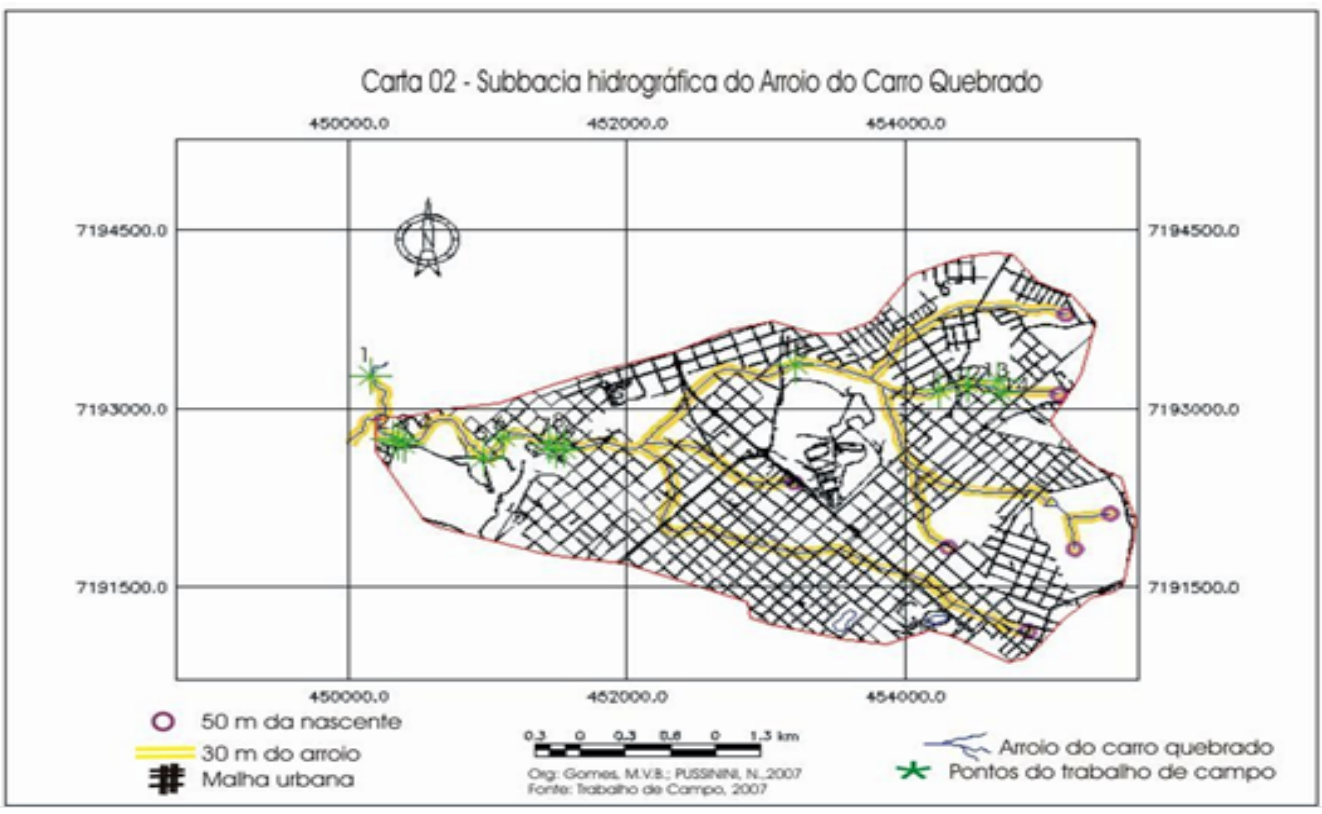

Figura 4. Sub-Bacia Hidrográfica do Arroio do Carro Quebrado 
bacia estudada. A partir desse trabalho é possível comparar os dados e ter uma contextualização espacial mais ampla sobre a área e suas condições ambientais.

\section{Considerações finais}

Para conseguirmos aplicar os princípios e objetivos do planejamento ambiental e, juntamente, conseguir gerir as cidades de maneira mais sustentável são necessárias ações conjuntas, que envolvem uma mobilização social, integrando a sociedade como um todo na luta por um ambiente urbano adequado. Além de uma forma diferenciada de se apropriar e produzir o espaço urbano, havendo assim uma reorganização ideológica, enfatizando os processos naturais/físicos e deixando de lado os atuais, voltados apenas para os aspectos econômicos.

Ressaltamos ainda que, de maneira concomitante, os instrumentos de gestão supracitados devem atuar de maneira decisiva e regulamentadoras sobre os processos de degradação ambientais urbanas, entendendo que é seu papel primordial dar condições para a aplicabilidade da gestão urbana ambiental. Tal processo é melhor elucidado por Basso, (2000, p.43. grifo nosso), dizendo que " $a$ melhoria ambiental nos centros urbanos exige uma série de medidas: vontade politica, recursos bumanos e financeiros, democracia, tecnologia, etc." Reconhece-se, assim que não é nada fácil obtê-la, sobretudo na atual sociedade que, sob a égide do capitalismo, tem sua prática voltada para produção e consumo de mercadorias.

Em caráter final, vemos que não bastam apenas campanhas de conscientização popular, se é que elas realmente existem. Para mudarmos essa situação, precisamos de ações que não fiquem restritas apenas a separar o lixo, por exemplo. Precisamos que esses valores, que alicerçam o capitalismo, sejam removidos e substituídos na sociedade, caso contrário, a crise só aumentará, ocasionando maiores e mais intensos impactos sobre o meio, numa situação cada vez mais crítica.

\section{Referências}

AZEVEDO, P. R. Passageiros da ilegalidade. A história de uma luta pela moradia. Edunioeste, 2002.157 p.

AZEVEDO, S. Desafios da habitação popular no Brasil: políticas recentes e tendências. In: Adauto Lucio Cardoso. (Org.). Habitação social nas metrópoles brasileiras. 1 ed. Porto Alegre: ANTAC, 2007. v. , p. 12-41.

BASSO, L. A. Desenvolvimento sustentável e qualidade ambiental nas cidades. In: SUERTEGARAY, D. M. A.; BASSO, L. A.; VERDUM, R. (Org.). Ambiente e Lugar no Urbano: A grande Porto Alegre. $1^{\circ}$ Ed. Porto Alegre: Editora Universidade/UFRGS, 2000. p. 35-46.

BITOUN, J. O embate entre as questões ambientais e sociais no urbano. In: CARLOS, A. F. A.; LEMOS, A. I. G. et. al. (Org.) Dilemas Urbanos: novas abordagens sobre a cidade.2. Ed. São Paulo: Contexto, 2005. p.299-307. 
BRASIL, Lei Federal N. 4771 de 29 de junho de 1965. Código Florestal Brasileiro. Dispõe sobre a tutela e competência legislativa das florestas brasileira. Diário Oficial [da] República Federativa do Brasil, Brasília, de 16 de setembro de 1965.

BRASIL, Constituição Federal (1998). Texto constitucional promulgado em 5 de outubro de 1988.

CARLOS, A. F. A. O Espaço Urbano: Novos Escritos sobre a Cidade. São Paulo. Labur Edições, 2007, 123 p.

CONSELHO NACIONAL DO MEIO AMBIENTE - CONAMA. Resolução N. 004 de 18 de setembro de 1985. Confere a Lei n. 6.938, de 31 de agosto de 1981, e tendo em vista o que estabelece a Lei n. 4771 de 15 de setembro de 1965, alterada pela Lei n. 6.535 de 15 de junho de 1978, e pelo que determina a Resolução CONAMA no 008/84, considera a necessidade de se estabelecerem as definições de Reservas Ecológicas as formações florísticas e as áreas de florestas de preservação permanente. Diário Oficial [da] República Federativa do Brasil, Brasília, de 20 de janeiro de 1986.

CONSELHO NACIONAL DO MEIO AMBIENTE - CONAMA. Resolução N. 001 de 23 de janeiro de 1986. Considera a necessidade de se estabelecerem as definições, as responsabilidades, os critérios básicos e as diretrizes gerais para uso e implementação da Avaliação de Impacto Ambiental com um dos instrumentos da Política Nacional do Meio Ambiente. Diário Oficial [da] República Federativa do Brasil, Brasília, de 17 de fevereiro de 1986.

CORRÊA, R. L. O espaço urbano. São Paulo: Contexto, 1995.

FERNANDES, E. Aspectos da Gestão Ambiental no Brasil. Revista Mineira De Saneamento Básico. [S.I], 2004.

GOMES, E. S. Expansão físico-territorial da cidade de Guarapuava - 1990 a 2005. Monografia (Especialização)- UNICENTRO, Guarapuava-PR, 2005.

GONÇALVES, C. W. P. Formação sócio-espacial e questão ambiental no Brasil. In: CHRISTOFOLETTI, A. et al. (Org). Geografia e Meio-Ambiente no Brasil. Hucitec. São Paulo. 1995.

GUERRA, A. I. T.; MARÇAL, M. S. Geomorfologia Ambiental. (Org.__). Rio de Janeiro: Bertand Brasil, 2006.

HARVEY, D. A justiça social e a cidade. São Paulo: Hucitec, 1980. 291p.

LEFF, E. Ecologia y capital:racionalidade ambiental, democracia participativa y desarrollo sustentable. Mexico: Siglo XXI/UNAM, 1994.

MAURO, A. C. Laudos Periciais em Depredações Ambientais. Rio Claro: Laboratório de planejamento Regional, DPR, IGCE. Unesp, 1997. 
MINISTÉRIO DAS CIDADES. Cadernos do ministério das cidades. Brasília: Mcidades Governo Federal, 2003.

PREFEITURA MUNICIPAL DE GUARAPUAVA. Plano Diretor Municipal. SURG - Secretaria de urbanização de Guarapuava. Guarapuava, 2006.

SANTOS, R. F. Planejamento ambiental: teoria e prática. São Paulo: Oficina de Textos, 2004.

SILVA, J. M. Valorização fundiária e expansão urbana recente de Guarapuava- PR. 1995. 167f. Dissertação (Mestrado em Geografia) - Centro de filosofia e ciências humanas. Universidade Federal de Santa Catarina, Florianópolis, 1995.

SOUZA, M. L. Mudar a Cidade: uma introdução crítica ao planejamento e à gestão urbanos. 4. ed. Rio de Janeiro, Bertrand Brasil, 2006.560p.

SPOSITO, M.E. B. O embate entre as questões ambientais e sociais no urbano. In: Dilemas Urbanos: novas abordagens sobre a cidade. (Org.) CARLOS, A. F. A.; LEMOS, A. I. G. et. al. 2. Ed. São Paulo: Contexto, 2005. p. 295-298. 